\title{
Analisis Komparasi Kinerja Keuangan Perbankan Syariah di Indonesia dan Malaysia Menggunakan Pendekatan Maqashid Sharia Index
}

Comparative analysis of Islamic banking financial performance between Indonesia and Malaysia using the maqashid sharia index

\section{Tiara Tresnawulan Barkah}

Program Studi D4 Keuangan Syariah, Politeknik Negeri Bandung

Email: tiara.tresnawulan.ksy16@polban.ac.id

\section{Dimas Sumitra Danisworo}

Jurusan Akuntansi, Politeknik Negeri Bandung

Email: dimas.danisworo@polban.ac.id

\section{Muhamad Umar Mai}

Jurusan Akuntansi, Politeknik Negeri Bandung

Email: umar.mai@polban.ac.id

\begin{abstract}
This research was conducted to analyze the performance of Islamic banking in Indonesia and Malaysia using the Maqashid Sharia Index. The research used Simple Additive Weigting method and independent analysis t-test. From this research it can be concluded that the performance value of Islamic banking in Indonesia using the Maqashid Sharia Index in 2014-2018 is 1.534 and Malaysia is 0.823. Based on the analysis of the independent t test, there is a significant difference between the average value of Islamic banks in Indonesia and Malaysia with a value of Tcount 2.819>Ttable 2.306, MSI's first goal is to obtain T-count value of $1.189<2.306$. The second objective of MSI is to get the T-count value of 2.327> 2.306. The third objective of MSI with Tcount value of $1.856<2.306 \mathrm{~T}$ table. This means that there is a significant difference in financial performance with MSI in Indonesia and Malaysia.
\end{abstract}

Keywords: $3-6$ word

\section{Pendahuluan}

Bank syariah sedang berkembang secara pesat di beberapa negara termasuk di Indonesia, Malaysia ataupun negara lainnya seperti di Timur Tengah hingga mencapai beberapa negara dengan penduduk muslim yang minoritas seperti Australia, Inggris, Amerika Serikat, dll. Perbankan Syariah hadir di Indonesia dan membawa nuansa lain dalam sistem keuangan dan perekonomian di Indonesia (Iwan, 2017), termasuk juga di berbagai negara lainnya. Melihat dari besarnya perkembangan bank syariah ini dapat membuktikan bahwa aturan dan prinsip yang digunakan pada bank syariah dapat diterima oleh berbagai pihak.

Data statistik yang terdapat dalam Islamic Financial Services Board (IFSB) mengatakan beberapa negara dengan tingkatan aset serta market share tertinggi pada tahun 2019 di dominasi oleh berbagai negara di Timur Tengah seperti Saudi Arabia, Kuwait, Qatar, dll, tetapi negara Asia juga ikut andil di dalamnya seperti Malaysia dan Indonesia. Data yang diperoleh Islamic Financial Services Board (IFSB) menunjukan bahwa hanya Indonesia dan Malaysia negara Asia khusuanya Asia 
Tenggara yang memiliki aset dan market share dengan pertumbuhan yang signifikan dibandingkan negara Asia lainnya yaitu Malaysia dengan nilai sebesar 26,5\% dan Indonesia dengan nilai sebesar 20,1\%. Data dapat dilihat di bawah ini:

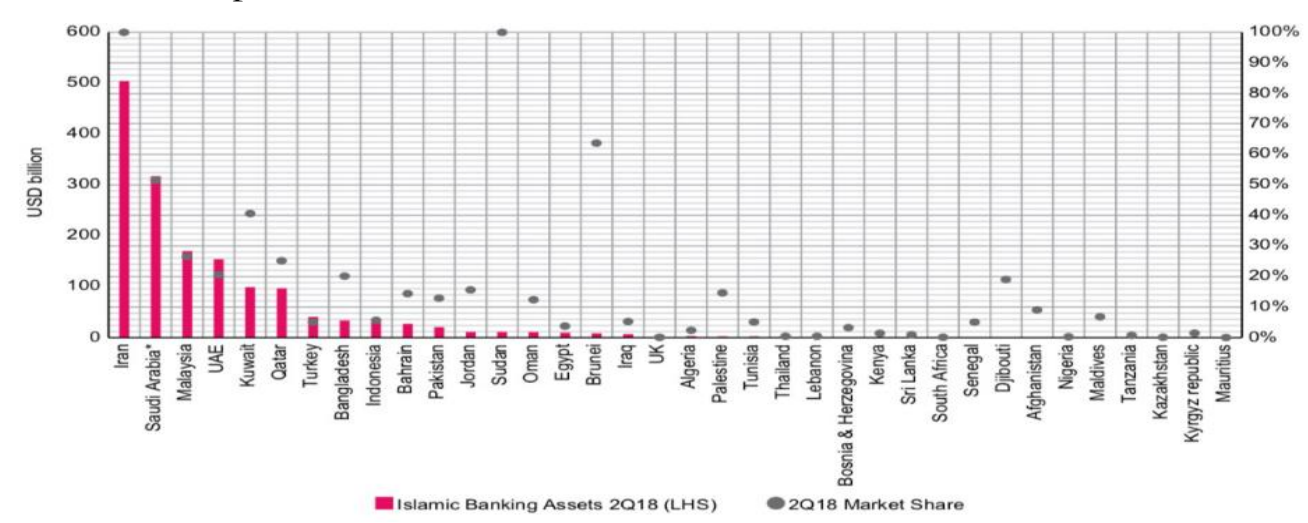

Gambar 1. Grafik Aset dan Market Share Perbankan Syariah

Sumber: PSIFIs IFSB Secretariat Workings

Indonesia dan Malaysia merupakan beberapa negara dengan mayoritas penduduk muslim, maka keduanya memiliki peran yang cukup penting dalam perkembangan bank syariah di dunia. Berdasarkan laporan keuangan selama lima tahun terakhir pada kedua negara, maka rata-rata perkembangan aset kinerja perbankan syariah di Indonesia mencapai 18.109.098.642,47 USD dan untuk Malaysia menunjukan perkembangan aset yang mencapai rata-rata sebesar 144.622.773.239,33 USD. Lihat tabel dibawah ini.

Tabel 1. Pertumbuhan Aset Bank Syariah d Indonesia dan Malaysia Tahun 2014-2018

\begin{tabular}{|c|c|c|c|c|c|}
\hline Tahun & $\begin{array}{c}\text { Aset Perbankan Syariah di } \\
\text { Malaysia (USD) }\end{array}$ & $\%$ & As & $\begin{array}{l}\text { Perbankan Syariah di } \\
\text { ndonesia (USD) }\end{array}$ & $\%$ \\
\hline 2013 & $105.219 .072 .452,91$ & & $\$$ & $13.052 .894 .843,47$ & \\
\hline 2014 & $117.652 .309 .346,66$ & $10,6 \%$ & $\$$ & $15.090 .051 .842,16$ & $13,5 \%$ \\
\hline 2015 & $132.028 .888 .144,30$ & $10,9 \%$ & $\$$ & $15.713 .088 .146,95$ & $4,13 \%$ \\
\hline 2016 & $143.403 .583 .870,59$ & $7,9 \%$ & $\$$ & $18.714 .094 .620,85$ & $19,1 \%$ \\
\hline 2017 & 161.121.847.689,96 & $11,0 \%$ & $\$$ & 21.205.723.081,93 & $13,3 \%$ \\
\hline 2018 & $190.344 .548 .639,73$ & $15,4 \%$ & $\$$ & $23.316 .128 .602,00$ & $9,95 \%$ \\
\hline
\end{tabular}

Sumber : Diolah dari OJK dan BNM 2015-2018

Berdasarkan Tabel 1. di atas, pertumbuhan aset bank syariah di Indonesia setiap tahunnya terus meningkat, walaupun pertumbuhan aset yang terus meningkat yang dialami oleh bank syariah di Indonesia tidak menjamin kinerja yang dilakukanya pun bagus (Setiawan dkk, 2020). Sementara, bank syariah di Malaysia pun memperlihatkan perkembangan yang baik setiap tahunnya. Tetapi, Indonesia memiliki aset yang lebih rendah di bandingkan Malaysia. Padalah menurut Badan Pusat Statistik (BPS) RI melaporkan data jumlah muslim di Indonesia pada tahun 2010 sebesar 209,12 juta jiwa dari jumlah penduduk 239,89 juta jiwa, sedangkan Sensus Populasi dan Perumahan Malaysia 2010 menyatakan bahwa jumlah penduduk Malaysia sebanyak 28,3 juta jiwa dan sekitar 67\% muslim artinya terdapat sekitar 18 juta jiwa muslim di Malaysia. Sudah selayaknya sebagai negara yang memiliki penduduk muslim terbesar, Indonesia dapat menjadi pelopor dan kiblat pengembangan keuangan syariah di dunia (Halim, 2012:1).

Untuk mengevaluasi hasil kinerja perbankan yang dapat disajikan dalam bentuk laporan keuangan, dilakukan dengan cara mengukur kinerja yang dilakukan pada perbankan sebagai 
gambaran pencapaian prestasi yang telah dilakukan oleh bank dalam kegiatan operasionalnya. Namun, menurut (Antonio dkk, 2012) evaluasi kinerja perbankan syariah yang digunakan saat ini cenderung memprioritaskan aspek pencarian laba. Sehingga, bila digunakan oleh perbankan syariah akan terdapat banyak kelemahan, seperti adanya nilai yang tidak sebanding dari penggunaan indikator kinerja perbankan konvensional karena perbankan syariah memiliki objek yang lebih luas (Mohammed et al, 2008).

Sehingga, usaha-usaha untuk mengembangkan evaluasi kinerja keuangan pada perbankan syariah yang seirama dengan maqashid sharia telah dilakukan oleh Hamed, dkk (2004), Shaukat (2008), Mohammed, Dzuljastri, dan Taib (2008), Mohammed dan Taib (2009). Dengan hasil yaitu menemukan dan merumuskan salah satu pengukuran yang dapat digunakan dalam pengukuran kinerja perbankan syariah yang sejalan dengan prinsip maqashid syariah atau disebut juga maqashid sharia index yang bertujuan agar terdapat sebuah pengukuran kinerja keuangan bagi bank syariah yang sejalan dengan tujuan-tujuan syariahnya.

Melihat perkembangan bank syariah di Indonesia dan Malaysia mendorong penulis untuk melakukan penelitian tentang kinerja perbankan syariah berdasarkan konsep Maqashid Sharia Index maka penulis memutuskan untuk melakukan penelitian yang berjudul "ANALISIS KOMPARASI KINERJA PERBANKAN SYARIAH DI INONESIA DAN MALAYSIA DENGAN PENDEKATAN MAQASHID SHARIA INDEX".

\section{Kajian Pustaka}

\subsection{Perbankan Syariah}

Perbankan Syariah menurut UU NO.21 Tahun 2008 tentang Perbankan Syariah adalah bank yang menjalankan kegiatan usaha berdasarkan prinsip syariah, yang diatur dalam fatwa Majelis Ulama Indonesia.

\subsection{Kinerja Keuangan}

Kinerja keuangan adalah analisis yang dilakukan untuk melihat sejauh mana suatu perusahaan sudah melaksanakan dengan berdasarkan dan menggunakan aturan-aturan pelaksanaan keuangan secara baik dan benar (Fahmi, 2012:2). Pengukuran kinerja merupakan bagian dari proses analisis kinerja keuangan (Siti Mardilia \& Setiawan, 2019).

Sementara kinerja dilihat dari pandangan ekonomi Islam merupakan segala kegiatan hasil kerja atau kinerja yang terikat dengan segala sesuatu yang dilakukan oleh individu sejalan dengan standar tertentu. Allah mengungkapkan dengan bentuk pahala dan siksaan terkait dengan produktifitas atau kinerja manusia. Allah SWT akan memberikan pahala bagi manusia yang melaksanakan perintahnya, sebaliknya Allah SW'T akan memberikan siksaan yang amat pedih bagi manusia yang melanggar perintahnya, maka dari itu sebagai seorang manusia hendaknya kita melakukan pekerjaan dengan sebaik-baiknya akan mendapatkan hasil yang baik bagi diri sendiri maupun untuk organisasi.

\subsection{Maqashid Sharia Index}

Maqashid sharia index adalah metode penilaian kinerja perbankan syariah yang menggunakan pendekatan Maqashid Syariah yang dirujuk dari konsep maqashid Abu Zahrah. Karena adanya ketidaksesuaian dalam penggunaan indikator kinerja perbankan konvensional dengan perbankan syariah maka konsep ini dikembangkan. Berikut model pengukuran kinerja maqashid syariab:

Tabel 2. Aplikasi Tujuan Perbankan Syariah Berdasarkan Maqashid Index

\begin{tabular}{|c|c|c|c|}
\hline Konsep & Dimensi & Elemen & Rasio Kinerja \\
\hline $\begin{array}{c}\text { Pendidikan } \\
\text { Individu }\end{array}$ & $\begin{array}{c}\text { D1. Meningkatkan } \\
\text { Pengetahuan }\end{array}$ & E1. Hibah Pendidikan & $\begin{array}{c}\text { R1.Hibah Pendidikan } \\
/ \text { Total Biaya }\end{array}$ \\
\cline { 2 - 3 } & & E2. Penelitian & R2. Biaya Penelitian / \\
\hline
\end{tabular}


Tiara Tresnawulan Barkah, Dimas Sumitra Danisworo, Muhamad Umar Mai

\begin{tabular}{|c|c|c|c|}
\hline \multirow[t]{4}{*}{ Konsep } & Dimensi & Elemen & Rasio Kinerja \\
\hline & & & Total Biaya \\
\hline & $\begin{array}{l}\text { D2. Menambah dan } \\
\text { meningkatkan } \\
\text { pengetahuan baru }\end{array}$ & E3. Pelatiahan & $\begin{array}{c}\text { R3. Biaya Pelatihan / } \\
\text { Total Biaya }\end{array}$ \\
\hline & $\begin{array}{c}\text { D3. Menciotakan } \\
\text { kesadaran masyarakat } \\
\text { akan keberadaan bank } \\
\text { syariah }\end{array}$ & E4. Publisitas & $\begin{array}{c}\text { R4. Biaya Publisistas / } \\
\text { Total Biaya }\end{array}$ \\
\hline \multirow[t]{3}{*}{$\begin{array}{l}\text { Menciptakan } \\
\text { Keadilan }\end{array}$} & D4. Kontrak yang adil & $\begin{array}{c}\text { E5. Pengembalian yang } \\
\text { adil }\end{array}$ & $\begin{array}{l}\text { R5. Profit Equalization } \\
\text { Reserves (PER) / Net } \\
\text { or Investment Income }\end{array}$ \\
\hline & $\begin{array}{l}\text { D5. Produk dan layanan } \\
\text { terjangkau }\end{array}$ & E6. Fungsi Distribusi & $\begin{array}{l}\text { R6. Mudharabah dan } \\
\text { Musharakah / Total } \\
\text { Pembiayaan }\end{array}$ \\
\hline & $\begin{array}{l}\text { D6. Penghapusan } \\
\text { Ketidakadilan }\end{array}$ & E7. Produk Non Bunga & $\begin{array}{l}\text { R7. Pendapatan Non } \\
\text { Bunga / Total } \\
\text { Pendapatan }\end{array}$ \\
\hline \multirow[t]{3}{*}{$\begin{array}{l}\text { Kepentingan } \\
\text { Umum }\end{array}$} & D7. Profitabilitas & E8. Rasio Laba & $\begin{array}{l}\text { R8. Laba Bersih / } \\
\text { Total Aset }\end{array}$ \\
\hline & $\begin{array}{l}\text { D8. Pendistribusian } \\
\text { kekayaan dan laba }\end{array}$ & E9. Pendapatan Personal & R9. Zakat / Net Aset \\
\hline & $\begin{array}{l}\text { D9. Investasi pada sektor } \\
\text { riil yang vital }\end{array}$ & $\begin{array}{l}\text { E10. Rasio investasi pada } \\
\text { sektor rill }\end{array}$ & $\begin{array}{c}\text { R10. Penyaluran } \\
\text { Investasi pada sektor } \\
\text { riil / Total Penyaluran } \\
\text { Investasi }\end{array}$ \\
\hline
\end{tabular}

Sumber : Mohammed dkk, 2008

Setelah mendapatkan hasil dari pengukuran di atas, selanjutnya melakukan wawancara dengan berbagai pakar syariah untuk melakukan vertifikasi berdasarkan model dan pembobotan pada setiap konsep dan elemen pengukuran (Muhamed dkk, 2008). Sehingga terbentuklah pembobotan menggunakan metode Simple Additive Weighting Method (SAW) seperti tabel dibawah ini:

Tabel 3. Aplikasi Bobot Rata - Rata Maqashid Sharia Index

\begin{tabular}{|c|c|c|c|}
\hline Konsep & $\begin{array}{c}\text { Average } \\
\text { Weight }(100 \%)\end{array}$ & Elemen & $\begin{array}{c}\text { Average } \\
\text { Weight }(100 \%)\end{array}$ \\
\hline \multirow{5}{*}{$\begin{array}{l}\text { Pendidikan } \\
\text { Individu }\end{array}$} & \multirow{5}{*}{30} & R1. Hibah Pendidikan & 24 \\
\hline & & R2. Penelitian & 27 \\
\hline & & R3. Pelatiahan & 26 \\
\hline & & R4. Publikasi & 23 \\
\hline & & Total & 100 \\
\hline \multirow{4}{*}{$\begin{array}{l}\text { 2. Menciptakan } \\
\text { Keadilan }\end{array}$} & \multirow{4}{*}{41} & R5. Pengembalian yang adil & 30 \\
\hline & & R6. Fungsi Distribusi & 32 \\
\hline & & R7. Produk Non Bunga & 38 \\
\hline & & Total & 100 \\
\hline \multirow{4}{*}{$\begin{array}{l}\text { 3. Kepentingan } \\
\text { Publik }\end{array}$} & \multirow{4}{*}{29} & R8. Rasio Laba & 30 \\
\hline & & R9. Pendapatan Personal & 33 \\
\hline & & R10. Rasio investasi pada sektor rill & 37 \\
\hline & & Total & 100 \\
\hline
\end{tabular}


Tabel 4. Rasio Kinerja Maqashid Sharia Index Tujuan Pertama pada Bank Syariah di Indonesia Tahun 2014-2018

\begin{tabular}{llcccc}
\hline \multirow{2}{*}{ No } & \multirow{2}{*}{ Nama Bank } & \multicolumn{3}{c}{ Rasio Rata-Rata Kinerja Tujuan 1 } \\
\cline { 3 - 6 } & & $\mathbf{R 1 . 1}$ & $\mathbf{R 1 . 2}$ & $\mathbf{R 1 . 3}$ & $\mathbf{R 1 . 4}$ \\
\hline $\mathbf{1}$ & Bank Panin Dubai & 0,008543 & 0,000000 & 0,000918 & 0,001618 \\
\hline $\mathbf{2}$ & Bank Syariah Mandiri & 0,000214 & 0,000027 & 0,000749 & 0,001443 \\
\hline $\mathbf{3}$ & Bank BNI Syariah & 0,018102 & 0,000000 & 0,002037 & 0,004478 \\
\hline $\mathbf{4}$ & Bank BRI Syariah & 0,019124 & 0,000000 & 0,000444 & 0,001918 \\
\hline $\mathbf{5}$ & Bank Muamalat & 0,022022 & 0,000193 & 0,000693 & 0,002424 \\
\hline
\end{tabular}

Sumber: Diolah oleh Penulis

Tabel 5. Rasio Kinerja Maqashid Sharia Index Tujuan Pertama pada Bank Syariah di Malaysia Tahun 2014-2018

\begin{tabular}{lllccl}
\hline \multirow{2}{*}{ No } & \multirow{2}{*}{ Nama Bank } & \multicolumn{4}{c}{ Rasio Rata-Rata Kinerja Tujuan 1 } \\
\cline { 3 - 6 } & & $\mathbf{R 1 . 1}$ & $\mathbf{R 1 . 2}$ & $\mathbf{R 1 . 3}$ & $\mathbf{R 1 . 4}$ \\
\hline $\mathbf{1}$ & CIMB Islamic Berhad & 0,002001 & 0,000000 & 0,000000 & 0,002010 \\
\hline $\mathbf{2}$ & Maybank Islamic Berhad & 0,000000 & 0,000000 & 0,001365 & 0,000769 \\
\hline $\mathbf{3}$ & RHB Islamic Berhad & 0,000000 & 0,000000 & 0,018229 & 0,007392 \\
\hline $\mathbf{4}$ & Bank Islam Malaysia & 0,000000 & 0,000000 & 0,000000 & 0,014033 \\
\hline $\mathbf{5}$ & Public Islamic Berhad & 0,000000 & 0,000000 & 0,000362 & 0,000343 \\
\hline
\end{tabular}

Sumber: Diolah oleh Penulis

1. Hibah Pendidikan (R1.1)

Hibah pendidikan dalam bank syariah berupa beasiswa ataupun dalam bentuk bantuan kepada lembaga. Berdasarkan data pada tabel di atas bank Muamalat Indonesia merupakan bank yang paling konsen dalam memberikan hibah pendidikan pada tahun 2014-2018 karena memiliki nilai tertinggi secara kumulatif yaitu 2,20\%, sementara untuk di Malaysia hanya bank CIMB Islamic Berhad yang menampilkan bantuan hibah pendidikan dengan nilai secara kumulatif hanya sebesar 0,20\%. Hal ini memperlihatkan bahwa kontribusi dalam bidang hibah pendidikan di Malaysia sangat jauh tertinggal dibandingkan di Indonesia. Sektor pendidikan adalah salah satu hal yang penting dalam membangun bangsa. Hibah pendidikan yang dilakukan oleh perbankan syariah diharapkan dapat membantu masyarakat dalam hal keberlangsungan pendidikan yang ditempuh sehingga dapat menghasilkan generasi-generasi yang unggul untuk membangun perekonomi berbasis Islam agar eksistensi bank syariah dapat semakin berkembang di tengah masyarakat dunia.

2. Penelitian (R1.2)

Rasio kedua dalam tujuan pertama Maqashid Shria Index ini adalah penelitian, yaitu dana yang akan di pergunakan untuk kebutuhan penelitian dan pengembangan bank syariah itu sendiri, terutama untuk pengembangan produk-produk untuk disesuaikan dengan prinsip syariah dan kebutuhan masyarakat di Indonesia hanya dua bank yang mengalokasikan dananya untuk kebutuhan penelitian dan pengembangan yaitu Bank Muamalat Indonesia dengan nilai kunulatif sebesar 0,019\% dan Bank Syariah Mandiri dengan nilai kumulatif dibawah BMI sebesar 0,0027\%, tentu saja nilai ini termasuk rendah dari total beban, dan bank lainnya tidak mengalokasikan dana untuk penelitian dan pengembangan. Sedangkan pada tabel 4.2 terlihat bahwa bank syariah di Malaysia tidak satupun mengalokasikan dananya untuk kebutuhan penelitian dan pengembangan.

Dari hasil penelitian di atas memperlihatkan sebaiknya perbankan syariah di Indonesia dan Malaysia harus lebih memperhatikan kegiatan penelitian dan pengembangan, karena dengan melakukan kegiatan ini dapat menghasilkan inovasi yang dapat membuat eksistensi perbankan syariah lebih melonjak. 
3. Pelatihan (R1.3)

Rasio ketiga pada tujuan pertama Maqashid Sharia Index yaitu dana yang akan digunakan oleh bank syariah untuk kegiatan pelatihan maupun pendidikan bagi para karyawan. Pelatihan yang dilakukan bank syariah terhadap karyawannya untuk meningkatkan soft skill dan hard skill, serta berupa kesempatan melanjutkan pendidikan yang lebih lanjut guna meningkatkan kualitas sehingga para karyawan dapat memberikan kinerja maksimal untuk perusahan. Berdasarkan analisis MSI di Indonesia menunjukan bahwa Bank BNI syariah merupakan bank syariah yang paling konsisten dalam melakukan pelatihan dan pendidikan bagi karyawan dengan rasio kumulatif 0,20\% mencakup lebih dari 100 pelatihan di berbagai bidang dan jabatan, Sementara di Malaysia hanya tiga bank yang melakukan pelatihan dan pendidikan bagi karyawan yaitu RHB Islamic Berhad dengan rasio kumulatif sebesar 1,82\%, kemudian disusul oleh Maybank Islamic Berhad sebesar $0,13 \%$ dan yang terakhir yaitu Public Islamic Berhad dengan rasio kumulatif hanya sebesar 0,03\%. Dapat dilihat bahwa pelatihan dan pendidikan karyawan lebih unggul dilakukan di Indonesia dari pada di Malaysia, padahal pelatihan dan pendidikan bagi karyawan sangat berguna selain untuk meningkatan soft skill dan hard skill juga membuat para karyawan lebih siap jika terjadi sesuatu yang tidak di inginkan salah satunya seperti terjadi krisis.

4. Publisitas (R1.4)

Rasio keempat adalah publisitas atau promosi. Promosi merupakan pondasi utama dalam memperkenalkan hal-hal yang berkaitan dengan bank syariah seperti produk-produk yang dikeluarkan, hingga keuntungan yang didapat masyarakat jika menjadi nasabah bank syariah. Berdasarkan tabel 4.1 presentasi publikasi tertinggi di Indonesia berdasarkan rasio kumulatif adalah bank BNI syariah dengan 0,45\%, selanjutnya di ikuti oleh bank Muamalat Indonesia, Bank BRI syariah, bank Panin Dubai Syariah dengan presentase masing-masing sebesar 0,24\%, 0,19\%, 0,16\% dan adalah bank dengan nilai rendah adalah bank mandiri syariah dengan rasio kumulatif sebesa 0,14\%. Sementara pada tabel 4.2 Bank Islam Malaysia memimpin dengan rasio kumulatif sebesar $1,40 \%$, disusul oleh RHB Islamic Berhad, CIMB Islamic Berhard, Maybank Islamic Berhad dengan rasio kumulatif masing-masing sebesar $0,70 \%, 0,20 \%, 0,07 \%$, dan rasio kumulatif terendah adalah Public Islamic Berhad yaitu sebesar 0,03\%. Maka dari hasil analisis di atas baik bank syariah di Indonesia ataupun di Malaysia terlihat sudah melaksanakan kegiatan promosi dengan baik.

\subsection{Tujuan Maqashid Shariah Index yang Kedua}

Tujuan Maqashid Sharia Index yang kedua ini memiliki tiga elemen, tetapi hanya dua elemen yang dipakai dalam pengukuran ini yaitu pengembalian yang adil dan fungsi distribusi, sedangkan untuk produk non bunga tidak digunakan karena pada laporan keuangan bank syariah yang diambil sebagai sampel tidak tercantum rasio pendapatan non bunga pada laporan keuangan masing-masing bank.

Tabel 6. Rasio Kinerja Maqashid Sharia Index Tujuan Kedua pada Bank Syariah di Indonesia Tahun 2014-2018

\begin{tabular}{lllc}
\hline \multirow{2}{*}{ No } & \multirow{2}{*}{ Nama Bank } & \multicolumn{2}{c}{$\begin{array}{c}\text { Rasio Rata-Rata Kinerja } \\
\text { Tujuan }\end{array}$} \\
\cline { 3 - 4 } & & R2.1 & R2.2 \\
\hline $\mathbf{1}$ & Bank Panis Dubai & 0,0000000 & 0,358341059 \\
\hline $\mathbf{2}$ & Bank Syariah Mandiri & 0,0000000 & 0,110895708 \\
\hline $\mathbf{3}$ & Bank BNI Syariah & 0,0000000 & 0,088717029 \\
\hline $\mathbf{4}$ & Bank BRI Syariah & 0,0000000 & 0,150678883 \\
\hline $\mathbf{5}$ & Bank Muamalat & 0,0000000 & 0,210158660 \\
\hline
\end{tabular}

Sumber: Diolah oleh Penulis 
Tabel 7. Rasio Kinerja Maqashid Sharia Index Tujuan Kedua pada Bank Syariah di Malaysia Tahun 2014-2018

\begin{tabular}{llcc}
\hline \multirow{2}{*}{ No } & \multicolumn{1}{c}{ Nama Bank } & \multicolumn{2}{c}{$\begin{array}{c}\text { Rasio Rata-Rata Kinerja } \\
\text { Tujuan }\end{array}$} \\
\cline { 3 - 4 } & & R2.1 & R2.2 \\
\hline $\mathbf{1}$ & CIMB Islamic Berhad & 0,0000000 & 0,0339787 \\
\hline $\mathbf{2}$ & Maybank Islamic Berhad & 0,0000000 & 0,0455161 \\
\hline $\mathbf{3}$ & RHB Islamic Berhad & 0,0000000 & 0,1049071 \\
\hline $\mathbf{4}$ & Bank Islam Malaysia & 0,0000000 & 0,0813762 \\
\hline $\mathbf{5}$ & Public Islamic Berhad & 0,0722177 & 0,0000553 \\
\hline
\end{tabular}

Sumber: Diolah oleh Penulis

1. Pengembalian yang Adil

Tujuan Maqashid Sharia Index yang kedua ini memiliki rasio utama yaitu pengemblian yang adil, sejalan dengan tujuan keadilan bahwa bank di tuntut adil dalam melakukan transaksi yaitu dengan cara memberikan hasil yang adil dan setara kepada nasabah, untuk mewujudkan transaksi yang adil rasio yang digunakan adalah Profit Equalization Reserve (PER). Berdasarkan hasil penelitian di atas pada tabel 6. bank syariah di Indonesia tidak menyediakan rasio PER pada laporan keuangannya. Sedangankan, pada tabel 7. hanya satu bank syariah di Malaysia yang terdapat rasio PER yaitu Public Islamic Berhard dengan rasio kumulatif sebesar 7,2\%. Penerapan PER pada perbankan syariah memang sangat terbatas karena biasanya metodologi perhitungan mudharabah diserahkan langsung oleh bank sentral kepada masing-masing bank dan tidak ada persyaratan pengungkapan tertentu pengawasan atas PER atau IRR (Ismail, 2019).

\section{Fungsi Distribusi}

Rasio kedua pada Maqashid Sharia Index tujuan kedua yaitu fungsi distribusi, dengan rasio mudharabah dan musyarakah. Berdasarkan hasil peneilitian pada tabel 6. di Indonesia rasio terbesar fungsi distribusi berdsarkan perhitungan kumulatif ditempati oleh bank Panin Dubai Syariah dengan nilai 35,83\%, sedangkan rasio kumulatif terendah ditempati oleh bank BNI Syariah dengan nilai $8,87 \%$. Sementara hasil perhitungan kumulatif pada tabel 7. di Malaysia terdapat perbadaan nilai yang cukup jauh di bandingkan di Indonesia, nilai kumulatif rasio terbesar sebesar 10,49\% ditempati oleh RHB Islamic bank, dan nilai rasio kumulatif terendah ditempati oleh Public Islamic Berhad hanya sebesar $0,01 \%$. Artinya bank di Indonesia lebih unggul dalam rasio mudharabah dan musyarakah, karena hanya sedikit produk mudharabah dan musyarakah yang tercantum dalam laporan keuangan masing-masing bank, dan didominasi oleh akad ba’i (jual beli).

\subsection{Tujuan Maqashid Shariah Index yang Ketiga}

Tujuan ketiga Maqashid Sharia Index ini adalah kepentingan umum. Terdapat tiga elemen dalam tujuan ini yaitu rasio laba, pendapatan personal dan rasio investasi pada sektor riil dari setiap elemen memiliki rasionya masing-masing.

Tabel 8. Rasio Kinerja Maqashid Sharia Index Tujuan Ketiga pada Bank Syariah di Indonesia Tahun 2014-2018

\begin{tabular}{clccc}
\hline \multirow{2}{*}{ No } & \multirow{2}{*}{ Nama Bank } & \multicolumn{3}{c}{$\begin{array}{c}\text { Rasio Rata-Rata Kinerja } \\
\text { Tujuan ke 3 }\end{array}$} \\
\cline { 3 - 5 } & & $\mathrm{R} 3.1$ & $\mathrm{R} 3.2$ & $\mathrm{R} 3.3$ \\
\hline $\mathbf{1}$ & Bank Panin Dubai & 0,0180512 & 0,0000130 & 0,3401767 \\
\hline $\mathbf{2}$ & Bank Syariah Mandiri & 0,0003679 & 0,0034234 & 0,0939251 \\
\hline $\mathbf{3}$ & Bank BNI Syariah & 0,0009206 & 0,0181351 & 0,0981261 \\
\hline $\mathbf{4}$ & Bank BRI Syariah & 0,0003323 & 0,0000238 & 0,0984132 \\
\hline
\end{tabular}


Tiara Tresnawulan Barkah, Dimas Sumitra Danisworo, Muhamad Umar Mai

$5 \quad$ Bank Muamalat $\quad 0,0000941 \quad 0,0239599 \quad 0,1063875$

Sumber: Diolah oleh Penulis.

Tabel 9. Rasio Kinerja Maqashid Sharia Index Tujuan Ketiga pada Bank Syariah di Malaysia Tahun 2014-2018

\begin{tabular}{clccc}
\hline \multirow{2}{*}{ No } & \multirow{2}{*}{ Nama Bank } & \multicolumn{3}{c}{$\begin{array}{c}\text { Rasio Rata-Rata Kinerja } \\
\text { Tujuan ke 3 }\end{array}$} \\
\cline { 3 - 5 } & & R3.1 & R3.2 & R3.3 \\
\hline $\mathbf{1}$ & CIMB Islamic Berhad & 0,00173 & 0,00000 & 0,08042 \\
\hline $\mathbf{2}$ & Maybank Islamic Berhad & 0,00055 & 0,00000 & 0,06656 \\
\hline $\mathbf{3}$ & RHB Islamic Berhad & 0,00144 & 0,00001 & 0,09243 \\
\hline $\mathbf{4}$ & Bank Islam Malaysia & 0,00269 & 0,00002 & 0,10074 \\
\hline $\mathbf{5}$ & Public Islamic Berhad & 0,00168 & 0,00000 & 0,08495 \\
\hline
\end{tabular}

Sumber: Diolah oleh Penulis.

1. Rasio Laba

Dalam suatu perusahaan laba adalah hal yang sangat penting karena laba dapat menggambarkan kesuksesan suatu perusahaan, bank syariah di Indonesia yang mencapai nilai rasio kumulatif tertinggi adalah bank Panin Dubai Syariah dengan nilai rasio 1,80\%, untuk bank Malaysia dapat dilihat bahwa bank dengan rasio kumulatif tertinggi adalah Bank Islam Malaysia dengan nilai rasio kumulatif sebesar 0,26\%, Dapat dilihat bahwa laba yang dihasilkan bank syariah di Indonesi tidak jauh berbeda dibandingkan di Malaysia.

\section{Zakat}

Dana zakat yang diberikan bank kepada masyarakat dalam koridor maqashid shariah adalah upaya bank syariah untuk menjaga lima tujuan syariah. Berdasarkan tabel di atas Bank Muamalat Indonesia merupakan bank dengan pemberian zakat tertinggi selama tahun 2014-2018 yaitu sebesar 2,39\%, Sedangkan pada bank syariah di Malaysia dengan kontribusi pemberi dana zakat adalah Bank Islam Malaysia dengan nilai rasio kumulatif sebesar 0,0015\%.

\section{Rasio Investasi pada Sektor Riil}

Rasio terakhir pada tujuan ketiga MSI ini merupakan penyaluran dana investasi yang digunakan untuk sektor riil, dana yang di investasikan dalam sektor riil adalah usaha bank syariah dalam membuat masyarakat menjadi semakin sejahtera dengan memberikan pembiayaan dalam bidang usaha pertanian, peternakan, dan sebagainya. Bank syariah yang paling konsisten untuk berinvestasi di sektor riil adalah bank Panin Dubai Syariah dengan nilai rasio kumulatif sebesar 34,01\%, Pada bank syariah di Malaysia dapat di lihat banwa Bank Islam Malaysia merupakan bank yang paling konsen memberikan investasinya pada sektor riil sebesar 10,07\%.

\subsection{Peringkat MSI}

Tabel 10. Kinerja Perbankan Syariah di Indonesia dan Malaysia berdasarkan Maqashid Sharia Index tahun 2014-2018

\begin{tabular}{clccccc}
\hline \multirow{2}{*}{ No } & \multicolumn{1}{c}{ Nama Bank } & $\begin{array}{c}\text { Tujuan } \\
\mathbf{1}\end{array}$ & $\begin{array}{c}\text { Tujuan } \\
\mathbf{2}\end{array}$ & $\begin{array}{c}\text { Tujuan } \\
\mathbf{3}\end{array}$ & Total & Peringkat \\
\hline $\mathbf{1}$ & Bank Panis Dubai & 0,05540 & 1,79171 & 0,43050 & 2,27760 & 1 \\
\hline $\mathbf{2}$ & Bank Syariah Mandiri & 0,01217 & 0,55448 & 0,48858 & 1,05523 & 6 \\
\hline $\mathbf{3}$ & Bank BNI Syariah & 0,12308 & 0,44359 & 0,58591 & 1,15258 & 4 \\
\hline $\mathbf{4}$ & Bank BRI Syariah & 0,10743 & 0,75339 & 0,49385 & 1,35467 & 3 \\
\hline $\mathbf{5}$ & Bank Muamalat & 0,12666 & 1,05079 & 0,65221 & 1,82966 & 2 \\
\hline
\end{tabular}


Tiara Tresnawulan Barkah, Dimas Sumitra Danisworo, Muhamad Umar Mai

\begin{tabular}{clccccc}
\hline $\mathbf{6}$ & CIMB Islamic Berhad & 0,01067 & 0,16989 & 0,33558 & 0,51614 & 10 \\
\hline $\mathbf{7}$ & $\begin{array}{l}\text { Maybank Islamic } \\
\text { Berhad }\end{array}$ & 0,02005 & 0,22758 & 0,43745 & 0,68508 & 9 \\
\hline $\mathbf{8}$ & RHB Islamic Berhad & 0,12810 & 0,52454 & 0,46943 & 1,12207 & 5 \\
\hline $\mathbf{9}$ & Bank Islam Malaysia & 0,07017 & 0,40688 & 0,51723 & 0,99428 & 7 \\
\hline $\mathbf{1 0}$ & Public Islamic Berhad & 0,00352 & 0,36136 & 0,43314 & 0,79803 & 8 \\
\hline Rata-rata MSI Indonesia & 0,08495 & 0,91879 & 0,53021 & 1,53395 & \\
\hline Rata-rata MSI Malaysia & 0,04650 & 0,33805 & 0,43856 & 0,82312 & \\
\hline
\end{tabular}

Berdasarkan hasil analisis dalam tabel 10. peringkat kinerja keuangan dapat disimpulkan bahwa bank Panin Dubai syariah berada pada peringkat pertama, dan CIMB Islamic Berhad berada diperingkat sepuluh. Jika dilihat dari tabel tersebut bank syariah dengan nilai total tujuan pertama pada tahun 2014-2018 adalah RHB Islamic Berhad yang berasal dari Malaysia dengan nilai 12,81\%, kemudian bank syariah dengan total nilai tujuan kedua tertinngi pada tahun 2014-2018 adalah Bank Panin Dubai Syariah yang bersalah dari Indonesia, dan bank syariah dengan total nilai tujuan ketiga tertingi pada tahun 2014-2018 adalan Bank Muamalat Indonesia. Selanjutnya dilihat dari total nilai rata-rata per negara, rata-rata perbankan syariah di Indonesia lebih unggul yaitu sebesar 1,53395, dibandingkan rata-rata perbankan syariah di Malaysia yaitu sebesar 0,82312.

\subsection{Perbedaan Kinerja Perbankan Syariah di Indonesia dan Malaysia Berdasarkan Maqashid Sharia Index}

1. Uji Normalitas

Tabel 11. Uji Normalitas One Sample Kolmogorov Smirnov Test

\begin{tabular}{lcccc}
\hline & $\begin{array}{c}\text { Tujuan 1 } \\
\text { (Pendidikan) }\end{array}$ & $\begin{array}{c}\text { Tujuan 2 } \\
\text { (Keadilan) }\end{array}$ & $\begin{array}{c}\text { Tujuan 3 } \\
\text { (Kemaslahatan) }\end{array}$ & MSI \\
\hline Normal Parametes: & 10 & 10 & 10 & 10 \\
\hline Mean & 0,06 & 0,628 & 0,484 & 1,179 \\
\hline Standart Deviation & 0,05 & 0,48 & 0,09 & 0,53 \\
\hline Sig: & $0,200^{1,2}$ & $0,200^{1,2}$ & $0,200^{1,2}$ & $0,200^{1,2}$ \\
\hline Decision: & $\begin{array}{c}\text { Retain the null } \\
\text { hypotesis }\end{array}$ & $\begin{array}{c}\text { Retain the } \\
\text { null hypotesis }\end{array}$ & $\begin{array}{c}\text { Retain the null } \\
\text { hypotesis }\end{array}$ & $\begin{array}{c}\text { Retain the null } \\
\text { hypotesis }\end{array}$ \\
\hline
\end{tabular}

Hasil uji normaltis terlihat bahwa untuk pendidikan, keadilan, kemaslahatan, dan MSI memiliki probabilitas signifikasi $0,200^{1,2}$ dan nilai $\alpha>0,05$ artinya hipotesis nol tidak ditolak atau pendidikan terdistribusi secara normal.

2. Independen $\mathrm{t}$-Test

Tabel 12. Tabel Hasil Uji Independent Sample t Test Tujuan Pertama

\begin{tabular}{|c|c|c|c|c|c|c|c|c|}
\hline \multirow[t]{2}{*}{ Variabel } & \multirow[t]{2}{*}{ Kelompok } & \multirow[t]{2}{*}{$\mathbf{N}$} & \multirow[t]{2}{*}{ Mean } & \multicolumn{2}{|c|}{$\begin{array}{l}\text { Levene's Test } \\
\text { for Equality of } \\
\text { Variances }\end{array}$} & \multicolumn{3}{|c|}{$\begin{array}{c}\text { t-test for Equality of } \\
\text { Means }\end{array}$} \\
\hline & & & & F & Sig. & $\mathrm{T}_{\text {hitung }}$ & df. & $\begin{array}{l}\text { Sig.(2- } \\
\text { tailed) }\end{array}$ \\
\hline \multirow{2}{*}{$\begin{array}{c}\text { Tujuan } 1 \\
\text { (Pendidikan) }\end{array}$} & Indonesia & 5 & ,084948 & \multirow[t]{2}{*}{,008 } & \multirow[t]{2}{*}{,933 } & \multirow[t]{2}{*}{1,189} & 8 & \multirow[t]{2}{*}{,269 } \\
\hline & Malaysia & 5 & ,046502 & & & & 7,979 & \\
\hline
\end{tabular}

$\mathrm{T}_{\text {hitung }}$ sebesar $1,189<2,306 \mathrm{~T}_{\text {tabel }}$ artinya Ho diterima $\mathrm{H}_{1}$ ditolak, berarti tidak ada perbedan yang berarti antara nilai rata-rata bank syariah di Indonesia dan di Malaysia. Selanjutnya analisis terakhir yaitu Sig.(2-tailed) pada bagian Equality of Means sebesar 0,269 > 0,05 yang berarti Ho 
diterima dan $\mathrm{H}_{1}$ ditolak atau tidak adanya perbedaan yang signifikan pada nilai tujuan pendidikan individu antara perbankan syariah di Indonesia dan di Malaysia. Selisih rata-rata mean sekitar 3,8\%.

Tabel 13. Tabel Hasil Uji Independent Sample t Test Tujuan Kedua

\begin{tabular}{|c|c|c|c|c|c|c|c|c|}
\hline \multirow[t]{2}{*}{ Variabel } & \multirow[t]{2}{*}{ Kelompok } & \multirow[t]{2}{*}{$\mathbf{N}$} & \multirow[t]{2}{*}{ Mean } & \multicolumn{2}{|c|}{$\begin{array}{c}\text { Levene's Test } \\
\text { for Equality of } \\
\text { Variances }\end{array}$} & \multicolumn{3}{|c|}{$\begin{array}{c}\text { t-test for Equality of } \\
\text { Means }\end{array}$} \\
\hline & & & & F & Sig. & $\mathrm{T}$ & df. & Sig. \\
\hline \multirow{2}{*}{$\begin{array}{l}\text { Tujuan } 2 \\
\text { (Keadilan) }\end{array}$} & Indonesia & 5 & 91879 & \multirow[t]{2}{*}{4,491} & \multirow[t]{2}{*}{, 067} & \multirow[t]{2}{*}{2,327} & 8 & \multirow[t]{2}{*}{, 048} \\
\hline & Malaysia & 5 & ,33805 & & & & 4 & \\
\hline
\end{tabular}

$\mathrm{T}_{\text {tabel }}$ sebesar 2,306, maka $\mathrm{T}_{\text {hitung }}$ sebesar 2,327>2,306 $\mathrm{T}_{\text {tabel }}$ artinya $\mathrm{H}_{2}$ diterima Ho ditolak berarti terdapat perbedan antara nilai rata-rata bank syariah di Indonesia dan di Malaysia. Selanjutnya analisis terakhir yaitu Sig.(2-tailed) pada bagian Equality of Means sebesar 0,048 < 0,05 yang berarti $\mathrm{H}_{2}$ diterima dan $\mathrm{H}_{\mathrm{o}}$ ditolak atau terdapat perbedaan yang signifikan pada nilai tujuan pembentukan keadilan antara perbankan syariah di Indonesia dan di Malaysia. Selisih ratarata mean sekitar $10 \%$.

Tabel 14. Tabel Hasil Uji Independent Sample t Test Tujuan Ketiga

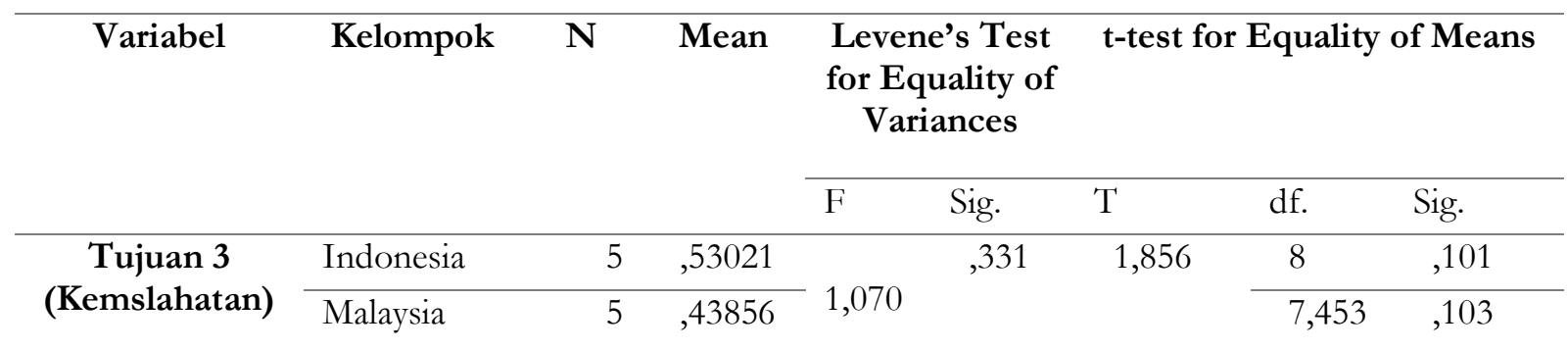

$\mathrm{T}_{\text {hitung }}$ sebesar $1,856<2,306 \mathrm{~T}_{\text {tabel }}$ artinya Ho diterima $\mathrm{H}_{3}$ ditolak berarti tidak ada perbedan yang berarti antara nilai rata-rata bank Syariah di Indonesia dan di Malaysia. Selanjutnya, analisis terakhir yaitu Sig. (2tailed) pada bagian Equality of Means sebesar 0,101> 0,05 yang berarti Ho diterima dan $\mathrm{H}_{3}$ ditolak atau tidak adanya perbedaan yang signifikan pada nilai tujuan kepentingan public antara perbankan Syariah di Indonesia dan di Malaysia. Selisih rata-rata mean sekitar 60\%.

Tabel 15. Tabel Hasil Uji Independent Sample t Test Maqashid Sharia Index

\begin{tabular}{|c|c|c|c|c|c|c|c|c|}
\hline \multirow[t]{2}{*}{ Variabel } & \multirow[t]{2}{*}{ Kelompok } & \multirow[t]{2}{*}{$\mathbf{N}$} & \multirow[t]{2}{*}{ Mean } & \multicolumn{2}{|c|}{$\begin{array}{c}\text { Levene's Test } \\
\text { for Equality of } \\
\text { Variances }\end{array}$} & \multicolumn{3}{|c|}{$\begin{array}{l}\text { t-test for Equality of } \\
\text { Means }\end{array}$} \\
\hline & & & & $\mathrm{F}$ & Sig. & $\mathrm{T}$ & df. & Sig. \\
\hline \multirow{2}{*}{$\begin{array}{l}\text { Maqashid } \\
\text { Sharia Index }\end{array}$} & Indonesia & 5 & 1,533948 & 4,343 &, 071 & 2,810 & 8 &, 023 \\
\hline & Malaysia & 5 &, 823120 & & & & 5,693 & ,033 \\
\hline
\end{tabular}

$\mathrm{T}_{\text {hitung }} 2,819>2,306 \mathrm{~T}_{\text {tabel }}$ artinya $\mathrm{H}_{4}$ diterima $\mathrm{H}_{\mathrm{o}}$ ditolak berarti terdapat perbedan yang berarti antara nilai rata-rata bank Syariah di Indonesia dan di Malaysia. Selanjutnya, analisis terakhir yaitu Sig. (2-tailed) pada bagian Equality of Means sebesar 0,023 < 0,05 yang berarti $\mathrm{H}_{4}$ diterima dan $\mathrm{H}_{\circ}$ ditolak atau terdapat perbedaan yang signifikan pada nilai Maqashid Sharia Indeks perbankan Syariah di Indonesia dan di Malaysia.

\section{Penutup}

Nilai kinerja perbankan Syariah di Indonesia menggunakan MSI pada tahun 2014-2018 rata- 
rata sebesar 1,534 dan di Malaysia rata-rata sebesar 0,823. Bank Syariah dengan nilai Maqashid Sharia Index terbaik pada tahun 2014-2018 adalah Bank Panin Dubai Syariah dari Indonesia dengan nilai 2,27760, selanjutnya bank dengan nilai Maqashid Sharia Index terendah pada tahun 2014-2018 adalah RHB Islamic Bank yang berasal dari Malaysia dengan nilai 0,51614.

Secara rata-rata keseluruhan objek dapat disimpulkan bahwa pada nilai Maqashid Sharia Index bank Syariah di Indonesia dan di Malaysia pada tahun 2014-2018 menghasilkan nilai untuk tujuan pertama MSI didapatkan nilai $\mathrm{T}_{\text {hitung }}$ sebesar $1,189<2,306 \mathrm{~T}_{\text {tabel }}$ artinya Ho diterima $\mathrm{H}_{1}$ ditolak, berarti tidak ada perbedan yang berarti antara nilai rata-rata bank Syariah di Indonesia dan di Malaysia, karena selisih nilai pada tujuan ini hanya 3,8\%. Kemudian, pada tujuan kedua MSI didapatkan nilai $\mathrm{T}_{\text {hitung }}$ sebesar 2,327 $>2,306 \mathrm{~T}_{\text {tabel }}$ artinya $\mathrm{H}_{2}$ diterima Ho ditolak berarti terdapat perbedan antara nilai rata-rata bank syariah di Indonesia dan di Malaysia, perbedaan nilai tersebut mencapai 60\%, lebih besar nilai MSI di Indonesia. Tujuan ketiga diketahui bahwa nilai $\mathrm{T}_{\text {hitung }}$ sebesar $1,856<2,306 \mathrm{~T}_{\text {tabel }}$ artinya Ho diterima $\mathrm{H}_{3}$ ditolak $_{s}$ berarti tidak ada perbedan yang berarti antara nilai rata-rata bank Syariah di Indonesia dan di Malaysia, karena nilai MSI hanya selisih sekitar 1\%. Selanjutnya, hipotesis terakhir yaitu $\mathrm{T}_{\text {hitung }}>\mathrm{T}_{\text {tabel }}$ yaitu 2,819 $>2,306$ artinya $\mathrm{H}_{4}$ diterima $\mathrm{H}_{\mathrm{o}}$ ditolak berarti terdapat perbedan yang signifikan antara nilai rata-rata bank syariah di Indonesia dan di Malaysia. Hasil kinerja perbankan Syariah di Indonesia yang dinilai menggunakan Maqashid Sharia Index pada tahun 2014-2018 lebih baik dibandingkan kinerja perbankan Syariah di Malaysia.

Untuk pihak perbankan Syariah baik di Indonesia maupun di Malaysia diharapkan untuk menjadikan Maqasid Sharia Index untuk menilai kinerja dalam operasionalnya sebagai bentuk upaya bank Syariah dalam menjaga lima prinsip umum dari maqashid sharia yaitu agama, jiwa, akal keturunan dan harta. Selain itu juga diharapakan untuk lebih memperhatikan aspek-aspek Syariah seperti :

- Meningkatkan pemberian dana hibah pendidikan baik berupa beasiswa kepada perorangan atau lembaga, penelitian dan pengembangan serta pelatihan kepada karyawan agar menghasilkan generasi-generasi yang unggul untuk membangun perekonomi berbasis Islam agar eksistensi bank syariah dapat semakin berkembang ditengah masyarakat dunia.

- Memperhatikan pemberian dana zakat, sebagai upaya untuk membantu meningkatkan kesejahteraan masyarakat, sehingga dapat mendorong laju ekonomi.

- Meningkatkan investasi pada sektor rill, sejalan tujuan dari bank syariah itu sendiri, yaitu menunjang pelaksanaan pembangunan nasional dalam rangka meningkatkan keadilan kebersamaan dan pemerataan kesejahteraan rakyat.

Untuk peneliti selanjutnya diharapkan dapat meneliti keseluruhan perbankan Syariah yang ada di Indonesia dan Malaysia dan menambah periode tahun penelitian agar mendapatkan kesimpulan yang lebih baik.

\section{Daftar Pustaka}

Antonio, Muhammad Syafii. 2012. An Analisys of Islamic Banking Performance: Maqashid Index Implementation in Indonesia and Yordania. IIUM Institute of Islamic Banking and Finance Journal of Islamic Finance, Vol. 1 No.1.

Badan Pusat Statistik (2010). https://www.bps.go.id diakses pada 10 Desember 2019.

Bank Negara Malaysia. 2019. Islamic Banking System: Statment of Aset 2019. www.bnm.gov.my diakses pada 13 November 2019.

Fahmi, I. (2012). Analisis kinerja keungan. Bandung: Alfa beta. http://repository.upi.edu/36268/diakses pada 15 November 2019.

Ghozali, Imam. 2011. "Aplikasi Analisis Multivariate Dengan Program SPSS”. Semarang: Badan Penerbit Universitas Diponegoro. 
Ghozali, Imam. (2013). Aplikasi Analisis Multivariat dengani program SPSS. Edis Ketujuh. Semarang: Badan Penerbit Universitas Diponegoro.

Halim, Alamsyah. 2012. "Perkembangan dan Prospek Perbankan Syariah Indonesia: Tantangan Dalam Menyongsong MEA 2015”. Milad ke-8 Ikatan Ahli Ekonomi Islam (IAEI).

Islamic Financial Industry. 2019. Stability Report 2019 www.ifsb.org diakses pada 10 November 2019.

Ismail. (2019). Implementasi Profit Equalization Reserve Perbankan Syariah di Indonesia dalam Tinjauan Fiqih. 4(1), 89.

Mardilia Siti Farihah, Setiawan. (2020). Determinan Intellectual Capital terhadap Profitabilitas di Bank Syariah : Pengujian Mediasi Kinerja Keuangan dan Kinerja Non Keuangan. 11(2), 151-165.

Mohammed, Dzuljastri dan Taib (2008). The Performance of Islamic Banking Based on The Maqashid Frammework. Makalah disampaikan pada IIUM Internasional Accounting Conference (INTAC IV). Putra Jaya Marroit. Malaysia.

Otoritas Jasa Keuangan. 2019. Laporan Perkembangan Kenangan Syariah di Indonesia 2019. www.ojk.go.id diakses pada 13 November 2019.

Setiawan, Putri Wulansari, Putri Rani. (2020). Pengukuran Tingkat Kinerja Keuangan dan Kinerja Non Keuangan pada Bank Syariah di Lima Negara Asia Dinamika Akuntansi, Keuangan dan Perbankan, 9(1), 69-78.

Setiawan, I. (2017). Peran Perbankan Syariah Terhadap Perekonomian di Indonesia (Pendekatan MSodel VAR/VECM). Tedc, 11(2), 172-178. 